\title{
Maternal Vitamin D Levels and the Risk of Offspring Attention-Deficit/Hyperactivity Disorder
}

\section{Sucksdorff, Minna}

2021-01

Sucksdorff , M , Brown , A S , Chudal , R , Surcel , H-M , Hinkka-Yli-Salomaki , S , Cheslack-Postava , K, Gyllenberg, D \& Sourander , A 2021, ' Maternal Vitamin D Levels and the Risk of Offspring Attention-Deficit/Hyperactivity Disorder ' , Journal of the American Academy of Child and Adolescent Psychiatry , vol. 60 , no. 1 , pp. 142-151 . https://doi.org/10.1016/j.jaac.2019.11.02

http://hdl.handle.net/10138/338124

https://doi.org/10.1016/j.jaac.2019.11.021

draft

Downloaded from Helda, University of Helsinki institutional repository.

This is an electronic reprint of the original article.

This reprint may differ from the original in pagination and typographic detail.

Please cite the original version. 


\section{Journal Pre-proof}

Maternal Vitamin D Levels and the Risk of Offspring Attention-Deficit/Hyperactivity Disorder

Minna Sucksdorff, MD, Alan S. Brown, MD, MPH, Roshan Chudal, MBBS, PhD, Heljä-Marja Surcel, PhD, Susanna Hinkka-Yli-Salomäki, PhLic, Keely CheslackPostava, PhD, David Gyllenberg, MD, PhD, Andre Sourander, MD, PhD

PII:

$$
\text { S0890-8567(19)32232-4 }
$$

DOI:

$$
\text { https://doi.org/10.1016/j.jaac.2019.11.021 }
$$

Reference: $\quad$ JAAC 2874

To appear in: Journal of the American Academy of Child \& Adolescent Psychiatry

Received Date: 13 August 2019

Revised Date: 11 November 2019

Accepted Date: 26 November 2019

Please cite this article as: Sucksdorff M, Brown AS, Chudal R, Surcel H-M, Hinkka-Yli-Salomäki S, Cheslack-Postava K, Gyllenberg D, Sourander A, Maternal Vitamin D Levels and the Risk of Offspring Attention-Deficit/Hyperactivity Disorder, Journal of the American Academy of Child \& Adolescent Psychiatry (2020), doi: https://doi.org/10.1016/j.jaac.2019.11.021.

This is a PDF file of an article that has undergone enhancements after acceptance, such as the addition of a cover page and metadata, and formatting for readability, but it is not yet the definitive version of record. This version will undergo additional copyediting, typesetting and review before it is published in its final form, but we are providing this version to give early visibility of the article. Please note that, during the production process, errors may be discovered which could affect the content, and all legal disclaimers that apply to the journal pertain.

(C) 2019 American Academy of Child and Adolescent Psychiatry 
Maternal Vitamin D Levels and the Risk of Offspring Attention-Deficit/Hyperactivity Disorder

RH = Maternal Vitamin D and Offspring ADHD

Editorial

Supplemental Material

Minna Sucksdorff, MD, Alan S. Brown, MD, MPH, Roshan Chudal, MBBS, PhD, HeljäMarja Surcel, PhD, Susanna Hinkka-Yli-Salomäki, PhLic, Keely Cheslack-Postava, PhD, David Gyllenberg, MD, PhD, Andre Sourander, MD, PhD

Accepted December 12, 2019

Drs. Sucksdorff, Chudal, Gyllenberg, and Sourander, and Ms. Hinkka-Yli-Salomäki are with the University of Turku, Finland. Drs. Sucksdorff and Sourander are also with Turku University Hospital, Finland. Drs. Brown, Cheslack-Postava, and Sourander are with Columbia University Medical Center, New York State Psychiatric Institute, New York, NY. Dr. Brown is also with the Columbia University Mailman School of Public Health, New York, NY. Dr. Sourander is also with INVEST Research Flagship, University of Turku, Finland (Principal Investigator). Dr. Surcel is with the Faculty of Medicine, University of Oulu, Finland, and Biobank Borealis of Northern Finland, Oulu University Hospital, Oulu, Finland. Dr. Gyllenberg is also with the National Institute of Health and Welfare, Helsinki, Finland, and Helsinki University Central Hospital, Helsinki, Finland.

This research was funded by the National Institute of Environmental Health Sciences (Grant number 5R01ES028125), the INVEST Research Flagship, the APEX Research Consortium, and the PSYCOHORTS consortium. This research was also funded by the Academy of Finland Flagship Program (decision number 320162), the Strategic Research Council at the Academy of Finland (decision number 303581), the National Institutes of Health (Grant number 1RO1ES028125-01), the Academy of Finland Health from Cohorts and Biobanks Program (decision number 308552), the Pediatric Research Foundation (M.S.), the Finnish Medical Foundation (M.S., D.G.), the University of Turku Graduate School (M.S.), the Finnish Brain Foundation (M.S.), The State Research Funding (M.S.), and the Brain and Behavior Research Foundation (D.G.).

Ms. Hinkka-Yli-Salomäki served as the statistical expert for this research.

Disclosure: Drs. Sucksdorff, Brown, Chudal, Surcel, Hinkka-Yli-Salomäki, CheslackPostava, Gyllenberg, and Sourander report no biomedical financial interests or potential conflicts of interest.

Correspondence to Andre Sourander, MD, PhD, Research Centre for Child Psychiatry, Department of Child Psychiatry, University of Turku and Turku University Hospital, Lemminkäisenkatu 3/Teutori (3rd floor), 20014 Turku, Finland; e-mail: andsou@utu.fi; minna.sucksdorff@utu.fi 


\section{Abstract}

Objective: Recent evidence has highlighted the importance of vitamin D to the development of the central nervous system. Some studies have shown an association between maternal vitamin D deficiency during pregnancy and offspring Attention-deficit/hyperactivity disorder (ADHD) symptoms based on parent- or teacher ratings. There are no previous studies on early pregnancy 25 -hydroxyvitamin $\mathrm{D}(25(\mathrm{OH}) \mathrm{D})$ levels and the risk of diagnosed offspring ADHD. Our aim was to examine maternal 25(OH)D levels in early pregnancy and offspring ADHD.

Method: In this nationwide population-based case-control study, 1067 ADHD cases born between 1998 and 1999 and diagnosed according to the International Classification of Diseases and 1067 matched controls, were identified from Finnish registers. Maternal 25(OH)D levels were measured using quantitative immunoassay from maternal sera, collected during the first trimester, and archived in the national biobank. Conditional logistic regression was used to examine the association between maternal $25(\mathrm{OH}) \mathrm{D}$ and offspring ADHD.

Results: There was a significant association between decreasing log-transformed maternal 25(OH)D levels and offspring ADHD both in the unadjusted analyses (OR 1.65, 95\% CI $1.33-2.05, P<.001)$ as well as in the analyses adjusting for maternal socio-economic status and age (OR 1.45, 95\% CI 1.15-1.81, $P=.002)$. Analyses by quintiles of maternal 25(OH)D levels in the lowest versus highest quintile revealed an adjusted odds ratio for offspring ADHD of $1.53(95 \%$ CI 1.11-2.12, $P=.010)$. 


\section{Journal Pre-proof}

Conclusion: This study demonstrated an association between low maternal 25(OH)D during pregnancy and an elevated risk for offspring ADHD. If replicated in independent samples, this finding may have significant public health implications.

Key words: ADHD, attention-deficit/hyperactivity disorder, vitamin D, maternal, prenatal 


\section{INTRODUCTION}

Attention-deficit/hyperactivity disorder (ADHD) is a common neurodevelopmental disorder, with an estimated worldwide prevalence of approximately $5 \% .{ }^{1}$ The disorder is characterized by symptoms of inattention, hyperactivity and impulsivity, and is associated with significant functional impairment. The etiology of ADHD is thought to be multifactorial with a strong genetic liability. ${ }^{2}$ However, environmental risk factors ${ }^{2-5}$ appear to play a role in the development of the disorder. ${ }^{6}$

Vitamin D has long been acknowledged for its essential role in bone health and development. The discovery that most tissues and cells in the body have a vitamin D receptor has provided new insights into its function. ${ }^{7}$ Evidence is growing of the importance of vitamin D on many extra-skeletal functions such as on the immune system, the central nervous system and on mental health. ${ }^{8,9}$ Some studies have shown an association between vitamin D deficiency during pregnancy and offspring autism and schizophrenia. ${ }^{10,11}$ Vitamin D, synthesized in the skin and from dietary sources, is metabolized in the liver to 25-hydroxyvitamin D 25(OH)D, which is used to determine a patient's vitamin D status. ${ }^{7}$

The studies examining the association of maternal $25(\mathrm{OH}) \mathrm{D}$ levels during pregnancy or those measured at birth among children with ADHD symptoms, have yielded contradictory results. Three studies ${ }^{12-14}$ have shown positive associations between lower maternal 25(OH)D levels and ADHD symptoms, while three other studies ${ }^{15-17}$ have found no association. Among these, two studies found a positive finding between maternal vitamin D deficiency in early pregnancy and a higher level of ADHD symptoms in offspring based on teacher ${ }^{12}$ or parent $^{13}$ ratings.

There are only two studies of maternal vitamin D deficiency and cases diagnosed with ADHD. ${ }^{15,16}$ A Danish study found no association between maternal 25(OH)D measured at 
gestational week 30 and offspring ADHD. ${ }^{15}$ A Swedish case-control study also reported no association between cord blood 25(OH)D at birth and ADHD. ${ }^{16}$ These studies are novel and potentially important, though there are limitations. First, the previous two studies of vitamin D and diagnosed ADHD included small to modest sample sizes $\left(\mathrm{N}=24^{15}\right.$ and $\mathrm{N}=202^{16}$ ADHD cases) that may limit statistical power to show significant associations. Second, the $25(\mathrm{OH}) \mathrm{D}$ measurements were based on samples taken in late pregnancy or at birth in the previous studies with diagnosed ADHD cases. The ascertainment of $25(\mathrm{OH}) \mathrm{D}$ from maternal serum collected during early pregnancy allows for examination of the effects of vitamin D deficiency during a period when events including neuronal proliferation and migration are taking place. ${ }^{13,18}$ Third, these previous studies offered limited adjustment for confounders, with no information on parental psychiatric diagnoses.

The present study is the first to examine maternal $25(\mathrm{OH}) \mathrm{D}$ levels in early pregnancy and diagnosed ADHD cases among the offspring in a large nationwide, population-based birth cohort. The study offered availability of information on several potential confounding factors. The data were collected from Finland, which is among the northernmost European countries with very little sun light exposure during the winter, and prior to 2004, when the national recommendation for vitamin D supplementation for pregnant women commenced. The consequent vulnerability to vitamin D deficiency allowed for enrichment of the exposure, further improving the power to investigate this association. Based on the previous findings on early pregnancy vitamin D levels and parent or teacher rated ADHD symptom scores, ${ }^{12,13}$ we hypothesized that low maternal $25(\mathrm{OH}) \mathrm{D}$ in early gestation is associated with increased odds of offspring ADHD diagnosis.

\section{METHOD}


The Finnish Prenatal study of ADHD is a nested case-control study derived from all singleton live births in Finland between 1991 and 2005 ( $\mathrm{N}=870$ 695) and followed up for ADHD diagnosis in the Care Register for Health Care (CRHC) until 2011. In the present study, maternal vitamin D level assessments utilizing maternal serum samples were performed for ADHD cases (F90) and matched controls born between 1998 and 1999 (see "Identification of cases and controls" below).

\section{Nationwide Registers}

The data used in this study were derived from three national registers: the Care Register for Health Care (CRHC), the Finnish Medical Birth Register (FMBR), and the Finnish Central Population Register (FCPR), which were linked using the personal identity codes.

The CRHC includes all public and private inpatient diagnoses since January 1, 1967, and outpatient diagnoses from specialized services since January 1, 1998. The diagnoses are based on the International Classification of Diseases (ICD). The ICD-10 has been used since $1996,{ }^{20}$ ICD-9 from 1987 to $1995,{ }^{21}$ and ICD-8 from 1969 to $1986^{22}$. A previous diagnostic validation study of the ADHD diagnoses in the CRHC, which are based on the ICD-criteria for hyperkinetic disorder, showed that $88 \%$ of the subjects examined met the $\underline{D S M-I V}$ diagnostic criteria for ADHD. ${ }^{23}$ The ICD-10 and DSM-IV criteria for hyperkinetic disorder / ADHD overlap, but the $D S M-I V$ criteria are generally broader and the ICD-criteria stricter. $^{24,25,26}$

The FMBR, established in 1987, contains comprehensive data on all newborns in Finland during the neonatal period up to seven days of age. Data include demographic characteristics, reproductive history, maternal health-related behaviors and perinatal events. 
The FCPR is a digital national archive containing basic demographic information about virtually all residents of Finland. The data include name, personal identification number, address, citizenship, native language, relatives, and date of birth and death (if applicable).

\section{Identification of Cases and Controls}

The ADHD cases were identified from the CRHC by using the personal identification code. In the present study the ADHD cases included singletons born in Finland between 1998 and 1999 and registered in the CRHC with the $I C D$ - 10 codes of hyperkinetic disorders F90.0, F90.1, F90.8, or F90.9 by 2011.

The controls were singleton offspring born in Finland and without a diagnosis in the CRHC of ADHD, conduct disorder (which could possibly be misdiagnosed ADHD), or severe intellectual disability. The controls were matched 1:1 to the case subjects on sex, date and place of birth. The controls were alive and residing in Finland at the date of diagnosis of the matched case. Among the 1320 cases and controls identified, sufficient sera was available for 1067 case-controls pairs. This study was approved by the ethical committees of the Hospital District of Southwest Finland, the data protection authorities at the National Institutes of Health and Welfare, and the New York State Psychiatric Institute IRB.

\section{Description of Biobank}

The Finnish Maternity Cohort (FMC) of the Northern Finland Biobank Borealis was established in 1983 as a nationwide effort of the National Institute for Health and Welfare. The FMC consists of approximately 2 million serum specimens collected during the first and early second trimester of pregnancy (5th to 95th percentile: months 2-4 of pregnancy) from over 950,000 women. The FMC covers virtually all pregnancies in Finland with archived prenatal serum specimens drawn for routine screening for congenital infections. Following 
informed consent, the remaining serum samples (one sample of 1-3 mLs for each pregnancy) are stored at $-25^{\circ} \mathrm{C}$ in a protected biorepository at the Northern Finland Biobank Borealis in

Oulu and are available for scientific research. ${ }^{19}$ All samples in the FMC can be linked with offspring by a unique personal identification code, which has been assigned to each resident of Finland since 1971.

\section{Serum 25(OH)D Measurement}

Maternal 25(OH)D measurements were carried out blind to case/control status. The 25(OH)D levels were measured in archived maternal serum using a chemiluminescence microparticle immunoassay (CMIA) by an Architect i2000SR automatic analyzer (Abbott Diagnostics) according to the manufacturer's instructions. We used the CMIA after evaluation of the assay by comparing the Architect i2000 method with high-performance liquid chromatography (HPLC). Comparing the 25(OH)D results showed a high correlation of 0.922 . Reproducibility of the CMIA was high $(\mathrm{R}=0.98)$. In addition, analysis of a set of commercially available quality control samples (six different samples) showed that the resulting levels of $25(\mathrm{OH}) \mathrm{D}$ were within the SD range of the reference results.

Coefficients of variation, derived from repeated quality control samples included in the assay with the study samples, were calculated. In control samples with "high" 25(OH)D levels (>100 nmol/L), the coefficient of variation $(\mathrm{CV})$ were $3.2 \%$, in samples with "medium" $25(\mathrm{OH}) \mathrm{D}$ levels $(\sim 80 \mathrm{nmol} / \mathrm{L})$, the $\mathrm{CV}$ was $3.1 \%$, and with "low" $25(\mathrm{OH}) \mathrm{D}$ levels $(<40$ $\mathrm{nmol} / \mathrm{L})$, the CV was 3.6\%. In blinded quality control pairs in which $25(\mathrm{OH}) \mathrm{D}$ levels were not known, the coefficients of variation were $1.1 \%$.

\section{Covariates}


A number of potential confounding factors suggested as having an association with offspring ADHD and maternal vitamin D levels were considered for inclusion in the analyses. ${ }^{3,4,27-36}$ We obtained information on the number of previous births, maternal socioeconomic status (SES), maternal age, self-reported smoking during pregnancy, gestational age (GA) and weight for gestational age (WGA, based on national sex-specific growth curves) ${ }^{37}$ from the FMBR. The maternal SES categories were existing occupation-based national classifications that are used in the FMBR: upper white collar workers, lower white collar workers, blue collar workers and others (e.g. students and housewives) or missing (if the data was not available). Information on maternal and paternal psychiatric diagnoses, ADHD diagnoses and maternal diagnoses of substance use disorder, were obtained from the CRHC. Information on maternal immigrant background was obtained from the FCPR and was included because certain ethnic minorities have an elevated risk for vitamin D deficiency during pregnancy ${ }^{31}$ and an increased likelihood of offspring ADHD diagnosis ${ }^{27}$. Information on gestational week and season of blood draw was obtained from the FMC. The seasons of blood collection were defined as: winter (December to February), spring (March to May), summer (June to August) and fall (September to November). As smokers are known to have lower 25(OH)D levels ${ }^{33}$ and self-reported smoking is underreported, ${ }^{29}$ we also included maternal cotinine, a biomarker of nicotine, in the covariate testing. Maternal cotinine levels were measured using quantitative immunoassays; a cotinine level of $20 \mathrm{ng} / \mathrm{ml}$ was used as a cut-point to define biomarker-based smoking status. ${ }^{29}$ A more detailed description of all covariates are presented in Tables 1 and 2.

\section{Statistical analysis}

We first examined the association of ADHD and maternal 25(OH)D defined as a continuous variable. Due to the skewed distribution, $25(\mathrm{OH}) \mathrm{D}$ was log-transformed before analysis in 
order to achieve a normal distribution. Second, we examined maternal 25(OH)D categorized into quintiles. The cut-points for the quintiles of maternal $25(\mathrm{OH}) \mathrm{D}$ levels were based on the distribution in the control group. We hypothesized that a significant association would be observed for maternal $25(\mathrm{OH}) \mathrm{D}$ classified in the lowest quintile compared with the reference group, which was defined as the highest quintile. In addition, we examined maternal $25(\mathrm{OH}) \mathrm{D}$ as a three-class categorical variable based on clinical categories: deficient $(25(\mathrm{OH}) \mathrm{D}<30 \mathrm{nmol} / \mathrm{L})$, insufficient $(25(\mathrm{OH}) \mathrm{D} 30-49.9 \mathrm{nmol} / \mathrm{L})$ and sufficient maternal vitamin D levels $(25(\mathrm{OH}) \mathrm{D}>50 \mathrm{nmol} / \mathrm{L})$, where the sufficient category was used as the reference group.

Categorically defined potential confounders were tested with Student's t and F-tests for the association with log-transformed maternal 25(OH)D among controls. For continuous potential confounders we used linear regression to test for the association with maternal $25(\mathrm{OH}) \mathrm{D}$ among controls. Conditional logistic regression for matched sets was used to test for the association between potential confounders and ADHD. In accord with the extant epidemiologic literature, covariates were considered as potential confounders and were included in the adjusted regression models if they were associated with both the exposure and the outcome at $\mathrm{P}<0.10 .{ }^{38} \mathrm{We}$ also tested the distribution of the covariates between the 1067 cases with available sera and the 253 cases lacking sera and thus excluded from the study.

Point and interval estimates of odds ratios were obtained by fitting conditional logistic regression models for matched pairs. Statistical significance was based on $\mathrm{P}<0.05$. All the statistical analyses were performed with SAS software (SAS 9.4, SAS Institute, Cary, N.C.).

\section{RESULTS}

The mean age at ADHD diagnosis was 7.3 years (SD: 1.9; range: 2-13.7 years). The median maternal 25(OH)D level among cases was $29.2 \mathrm{nmol} / \mathrm{L}$ (range: $8.9-115.6 \mathrm{nmol} / \mathrm{L}, \mathrm{Q} 1=21.5$ 
$\mathrm{nmol} / \mathrm{L}, \mathrm{Q} 3=41.7 \mathrm{nmol} / \mathrm{L}$ ) and $32.2 \mathrm{nmol} / \mathrm{L}$ (range: $7.5-132.5 \mathrm{nmol} / \mathrm{L}, \mathrm{Q} 1=23.2 \mathrm{nmol} / \mathrm{L}$, Q3=45.4 nmol/L) among controls. The mean gestational week of maternal blood draw was 10.7 (SD: 3.7) for cases and 10.6 (SD: 3.1) for controls. The gender distribution was $85.5 \%$ male and $14.5 \%$ female in cases and in controls. The distribution of maternal $25(\mathrm{OH}) \mathrm{D}$ by case-control status in quintiles is presented in Figure 1.

Among the covariates, maternal age, SES, self-reported smoking, psychopathology, substance abuse, ADHD diagnosis, immigrant status, number of previous births, and cotinine levels; paternal psychopathology and ADHD diagnosis; and offspring GA and WGA were associated with offspring ADHD with $\mathrm{P}<0.1$ (Table 1). Maternal age, SES and season of blood collection were associated with maternal 25(OH)D level with $\mathrm{P}<0.1$ (Table 2). Maternal SES and age were associated with both offspring ADHD and maternal 25(OH)D level, and were thus adjusted for in the multivariate analyses.

The season of blood collection did not differ between the cases and the controls $(P=.86)$. The mean gestational week of maternal blood draw did not differ between the cases and the controls $(P=.54)$. The cases and the controls were originally also matched on the date (and place) of birth hindering any potential effect of season.

The distribution of the covariates did not differ between the 1067 included cases and the 253 without available sera. (see Table S1, available online)

As shown in Table 3, there was a significant association between decreasing log-transformed maternal 25(OH)D levels and increasing risk of offspring ADHD both in the unadjusted (OR $1.65,95 \%$ CI 1.33-2.05, $P<.001)$ and adjusted analyses (OR 1.45, 95\% CI 1.15-1.81, $P=.002$ ). To test for possible mediation by WGA or maternal cotinine levels, or for confounding by maternal psychiatric history, we ran additional analyses with WGA, maternal psychiatric history and maternal biomarker-based smoking-status added to the adjusted 
model. The associations remained significant in these analyses (see Table 3). Furthermore, an additional analysis adjusting for maternal immigrant background (mother born / not born in Finland) also did not change the results (OR 1.44, 95\% CI 1.14-1.81, $P=.002$ ). For further reassurance, we ran additional analyses adjusting also for the remaining covariates associated with offspring ADHD and the results remained significant in all additional analyses (see Table S2, available online)

Given the established differences in the risk of ADHD by sex, we tested for sex-by-25(OH)D interaction and found no evidence of effect modification by sex on the relationship between maternal 25(OH)D and ADHD $(P=.84)$. In addition, we tested for a possible effect of the age at diagnosis and found no interaction between the age at ADHD diagnosis and maternal 25(OH)D levels $(P=.78)$.

The distribution of maternal $25(\mathrm{OH}) \mathrm{D}$ in quintiles by case-control status is presented in Table

4. The odds ratio for ADHD among offspring of mothers in the lowest vitamin D quintile compared to the highest quintile was $1.83(95 \% \mathrm{CI} 1.34-2.51, P<.001)$ in the unadjusted model and 1.53 (95\% CI 1.11-2.12, $P=.010$ ) in the adjusted model (Table 4). In the additional analyses when maternal 25(OH)D levels were classified into three clinical categories, maternal vitamin D deficiency $(25(\mathrm{OH}) \mathrm{D}<30 \mathrm{nmol} / \mathrm{L})$ was associated with offspring ADHD in the unadjusted analyses (OR 1.51, $95 \%$ CI 1.15-1.99, $P=.003$ ) as well as when adjusted for maternal age and SES (OR 1.34, 95\% CI 1.008-1.78 $P=.044$ ). (See Table S3, available online)

\section{DISCUSSION}

The present study is the first to demonstrate an association between low maternal $25(\mathrm{OH}) \mathrm{D}$ level in early to mid-pregnancy and an elevated risk for diagnosed ADHD in the offspring in a large nationwide, population-based sample. The association was observed both when 
vitamin $\mathrm{D}$ was analyzed as a linear and as a categorical variable. These findings are the strongest evidence to date of a link between developmental vitamin D deficiency and offspring ADHD. Our results are in accord with two studies showing associations between lower maternal $25(\mathrm{OH}) \mathrm{D}$ levels in early pregnancy and higher levels of teacher ${ }^{12}$ or parent $^{13}$ rated offspring ADHD symptoms.

There are biologically plausible explanations for the association between developmental vitamin D deficiency and an increased risk of offspring ADHD. Early pregnancy is a critical period for fetal brain development, which is a complex process influenced by the individual's genotype and the in utero environment. ${ }^{11,39}$ Low vitamin D levels result from inadequate sun exposure, low vitamin D intake from diet as well as physiological risk factors such as obesity and skin color. ${ }^{35}$ The present findings suggest that insufficient in utero vitamin D may adversely influence fetal programming and expose the offspring to a suboptimal environment resulting in possible ADHD. Vitamin D receptors are expressed in the brain, and research has shown that vitamin D affects brain function through regulation of calcium signaling, neurotrophic and neuroprotective actions, neuronal differentiation, maturation and growth. ${ }^{8,9,40}$

The present findings are supported by observations from animal studies, which have shown that developmental vitamin D deficiency is associated with a range of persistent neurochemical and behavioral outcomes. ${ }^{8}$ Depleting vitamin D leads to changes in multiple neurotransmitters in the brains of newborn rats. ${ }^{41}$ One finding among vitamin D deficient rats has been altered dopamine signaling. ${ }^{8}$ Early vitamin D deficiency may enhance hyperlocomotion and increase activity among rats. ${ }^{42}$ These mechanisms have previously been linked to schizophrenia and autism, but may well have relevance to ADHD as well, notably 
alterations in ontogeny of dopamine systems, novelty-induced hyperlocomotion, and disrupted latent inhibition, indicative of abnormal attentional processing. ${ }^{43,44}$

Despite the marked reduction in the prevalence of many nutritional deficiencies in the developed world, vitamin D deficiency still remains common, and therefore the present study could have significant public health implications. ${ }^{7,45}$ Vitamin D deficiency is especially prevalent among pregnant women, and this results in low vitamin D levels in the fetus and offspring in early life. ${ }^{46} \mathrm{~A}$ recent meta-analysis concluded that higher circulating prenatal $25(\mathrm{OH}) \mathrm{D}$ levels may have positive effects on the offspring's neurodevelopment and reduce the risk of ADHD and autism-related traits. ${ }^{47}$ Interestingly, another recent meta-analysis showed that $25(\mathrm{OH}) \mathrm{D}$ serum concentrations were also lower among children and adolescents with ADHD. ${ }^{48}$ Although a cconsensus has not been reached regarding the criteria of sufficient concentrations of $25(\mathrm{OH}) \mathrm{D}$ for pregnant women, the Institute of Medicine, in their updated report from $2011,{ }^{49}$ suggested that $25(\mathrm{OH}) \mathrm{D}$ concentrations of at least $30 \mathrm{nmol} / \mathrm{L}$ would prevent deficiency with respect to bone health and that $50 \mathrm{nmol} / \mathrm{L}$ would be sufficient in most people. ${ }^{50}$ The maternal $25(\mathrm{OH}) \mathrm{D}$ concentrations in our study were low with a median value of $29.2 \mathrm{nmol} / \mathrm{L}$ among mothers of cases and $32.2 \mathrm{nmol} / \mathrm{L}$ among mothers of controls. Of note, in the lowest quintile, which as reported above showed the strongest association with ADHD, the maternal 25(OH)D concentrations were 7.5 to $21.9 \mathrm{nmol} / \mathrm{L}$. The overall low vitamin $\mathrm{D}$ concentrations could be attributed to the fact that maternal sera were collected from pregnancies between 1998 and 1999, long before vitamin D supplementation recommendations for pregnant women in Finland began in 2004. In addition, Finland is situated in Northern Europe in a far northern latitude (between $60^{\circ}$ and $70^{\circ} \mathrm{N}$ ) with long periods of little exposure to sunlight throughout the year, limiting vitamin D synthesis in the skin. 
Journal Pre-proof

The strengths of the present study include the large nationwide sample, assessment of maternal $25(\mathrm{OH}) \mathrm{D}$ concentrations based on prospectively collected sera in the first and early second trimesters, and control for a wide range of potential confounders including date of birth, place of birth, maternal psychiatric history, immigration background, child's weight for gestational age and prenatal nicotine exposure.

There are several limitations that must be considered. First, the ADHD subjects in this study included only those who had been referred to specialized services and likely represent the more severe ADHD cases. Of note, the cases were diagnosed with the ICD-criteria for hyperkinetic disorder that are generally stricter than the $D S M$-criteria for ADHD. ${ }^{24,25}$ The validity of the ADHD diagnoses in the CRHC have been evaluated previously with $88 \%$ of the register-diagnosed patients examined by telephone interviews meeting the $D S M-I V$ criteria for ADHD. ${ }^{23}$ Second, the number of parents diagnosed with ADHD was low, possibly because ADHD was not a widely used diagnosis in Finland in the parental generation. Third, we were able to assess maternal $25(\mathrm{OH}) \mathrm{D}$ at only one time point of pregnancy. However, it is likely that the mother's $25(\mathrm{OH}) \mathrm{D}$ concentration was similar throughout pregnancy. ${ }^{36}$ Fourth, it is possible that unmeasured factors confounded the association of vitamin D deficiency and ADHD; unfortunately, maternal body mass index data were not available. Furthermore, lower maternal $25(\mathrm{OH}) \mathrm{D}$ could be an indicator of other prenatal risk factors such as a poorer diet (i.e. containing less beneficial fatty acids) or lack of compliance with general health recommendations for prenatal care. However, our adjusted model did include maternal SES, maternal age, and maternal psychiatric history, which are related to those factors. Furthermore, our additional mediation analyses by child's weight for gestational age and maternal cotinine levels did not change the results. Fifth, we did not have data on maternal medications with possible effects on maternal vitamin D levels. Sixth, the generalizability of the findings to various ethnic groups with differing vulnerability to vitamin D deficiency is 
low due to the low number of immigrant mothers. Future studies with ethnically more diverse samples are needed.

This is the first population-based study to demonstrate an association between low maternal vitamin D level in early to mid-pregnancy and an increased risk for offspring ADHD diagnosis. If these findings are replicated, they may have public health implications for vitamin D supplementation and perhaps changing life-style behaviors during pregnancy to ensure optimal maternal vitamin D levels. 


\section{REFERENCES}

1. Sayal K, Prasad V, Daley D, Ford T, Coghill D. ADHD in children and young people: prevalence, care pathways, and service provision. Lancet Psychiatry. 2018;5(2):175-186. doi:10.1016/S2215-0366(17)30167-0

2. Thapar A, Cooper M. Attention deficit hyperactivity disorder. Lancet. 2016;387(10024):1240-1250. doi:10.1016/S0140-6736(15)00238-X

3. Sucksdorff M, Lehtonen L, Chudal R, et al. Preterm Birth and Poor Fetal Growth as Risk Factors of Attention-Deficit/ Hyperactivity Disorder. Pediatrics. 2015;136(3):e599-608. doi:10.1542/peds.2015-1043

4. Chudal R, Joelsson P, Gyllenberg D, et al. Parental age and the risk of attentiondeficit/hyperactivity disorder: a nationwide, population-based cohort study. J Am Acad Child Adolesc Psychiatry. 2015;54(6):487-494.e1. doi:10.1016/j.jaac.2015.03.013

5. Silva D, Colvin L, Hagemann E, Bower C. Environmental risk factors by gender associated with attention-deficit/hyperactivity disorder. Pediatrics. 2014;133(1):e14-22. doi:10.1542/peds.2013-1434

6. Thapar A, Cooper M, Eyre O, Langley K. What have we learnt about the causes of ADHD? J Child Psychol Psychiatry. 2013;54(1):3-16. doi:10.1111/j.14697610.2012.02611.x

7. Holick MF. Vitamin D deficiency. N Engl J Med. 2007;357(3):266-281. doi: 10.1056/NEJMra070553

8. Groves NJ, McGrath JJ, Burne TH. Vitamin D as a neurosteroid affecting the developing and adult brain. Аппи Rev Nutr. 2014;34:117-141. doi:10.1146/annurev-nutr-071813105557 
9. Kesby JP, Eyles DW, Burne TH, McGrath JJ. The effects of vitamin D on brain development and adult brain function. Mol Cell Endocrinol. 2011;347(1-2):121-127. doi:10.1016/j.mce.2011.05.014

10. Vinkhuyzen AAE, Eyles DW, Burne THJ, et al. Gestational vitamin D deficiency and autism spectrum disorder. BJPsych Open. 2017;3(2):85-90. doi:10.1192/bjpo.bp.116.004077

11. Eyles DW, Trzaskowski M, Vinkhuyzen AAE, et al. The association between neonatal vitamin D status and risk of schizophrenia. Sci Rep. 2018;8(1):17692. doi:10.1038/s41598-018-35418-Z

12. Morales E, Julvez J, Torrent M, et al. Vitamin D in Pregnancy and Attention Deficit Hyperactivity Disorder-like Symptoms in Childhood. Epidemiology. 2015;26(4):458465. doi:10.1097/EDE.0000000000000292.

13. Daraki V, Roumeliotaki T, Koutra K, et al. High maternal vitamin D levels in early pregnancy may protect against behavioral difficulties at preschool age: the Rhea motherchild cohort, Crete, Greece. Eur Child Adolesc Psychiatry. 2018;27(1):79-88. doi:10.1007/s00787-017-1023-x

14. Mossin MH, Aaby JB, Dalgård C, Lykkedegn S, Christesen HT, Bilenberg N. Inverse associations between cord vitamin $\mathrm{D}$ and attention deficit hyperactivity disorder symptoms: A child cohort study. Aust N Z J Psychiatry. 2017;51(7):703-710. doi:10.1177/0004867416670013

15. Strøm M, Halldorsson TI, Hansen S, et al. Vitamin D measured in maternal serum and offspring neurodevelopmental outcomes: a prospective study with long-term follow-up. Ann Nutr Metab. 2014;64(3-4):254-261. doi:10.1159/000365030 
16. Gustafsson P, Rylander L, Lindh CH, et al. Vitamin D Status at Birth and Future Risk of Attention Deficit/Hyperactivity Disorder (ADHD). PLoS One. 2015;10(10):e0140164. doi:10.1371/journal.pone.0140164

17. Keim SA, Bodnar LM, Klebanoff MA. Maternal and cord blood 25(OH)-vitamin D concentrations in relation to child development and behaviour. Paediatr Perinat Epidemiol. 2014;28(5):434-444. doi:10.1111/ppe.12135

18. Wang R, Dai G, Takahashi E. High Resolution MRI Reveals Detailed Layer Structures in Early Human Fetal Stages: In Vitro Study with Histologic Correlation. Front Neuroanat. 2015;9:150. doi:10.3389/fnana.2015.00150

19. Gissler M, Surcel HM. Combining health register data and biobank data. Stat J IAOS. 2012;28(1-2):53-58. doi:10.3233/SJI-2012-0744

20. World Health Organization (WHO). International classification of diseases, tenth revision (ICD-10). Geneva, Switzerland: World Health Organization; 1992.

21. World Health Organization (WHO). International classification of diseases, ninth revision (ICD-9). Geneva, Switzerland: World Health Organization; 1977.

22. World Health Organization (WHO). International Classification of Diseases, Eighth Revision. Geneva, Switzerland: World Health Organization; 1967.

23. Joelsson P, Chudal R, Gyllenberg D, et al. Demographic Characteristics and Psychiatric Comorbidity of Children and Adolescents Diagnosed with ADHD in Specialized Healthcare. Child Psychiatry Hum Dev. 2016;47(4):574-582. doi:10.1007/s10578-0150591-6

24. Tripp G, Luk SL, Schaughency EA, Singh R. DSM-IV and ICD-10: a comparison of the correlates of ADHD and hyperkinetic disorder. J Am Acad Child Adolesc Psychiatry. 1999;38(2):156-164. doi:10.1097/00004583-199902000-00014 
25. Lahey BB, Pelham WE, Chronis A, et al. Predictive validity of ICD-10 hyperkinetic disorder relative to DSM-IV attention-deficit/hyperactivity disorder among younger children. J Child Psychol Psychiatry. 2006;47(5):472-479. doi:10.1111/j.14697610.2005.01590.x

26. Santosh, P. J., Taylor, E., Swanson, J. et al. Refining the diagnoses of inattention and overactivity syndromes: A reanalysis of the Multimodal Treatment study of attention deficit hyperactivity disorder (ADHD) based on ICD-10 criteria for hyperkinetic disorder. Clinical Neuroscience Research, 5(5-6), 307-314

27. Lehti V, Chudal R, Suominen A, Gissler M, Sourander A. Association between immigrant background and ADHD: a nationwide population-based case-control study. $J$ Child Psychol Psychiatry. 2016;57(8):967-975. doi:10.1111/jcpp.12570

28. Joelsson P, Chudal R, Uotila J, et al. Parental psychopathology and offspring attentiondeficit/hyperactivity disorder in a nationwide sample. J Psychiatr Res. 2017;94:124-130. doi:10.1016/j.jpsychires.2017.07.004

29. Sourander A, Sucksdorff M, Chudal R, et al. Prenatal Cotinine Levels and ADHD Among Offspring. Pediatrics. 2019;143(3):e20183144. doi:10.1542/peds.2018-3144

30. Miliku K, Vinkhuyzen A, Blanken LM, et al. Maternal vitamin D concentrations during pregnancy, fetal growth patterns, and risks of adverse birth outcomes. Am J Clin Nutr. 2016;103(6):1514-1522. doi:10.3945/ajcn.115.123752

31. Eggemoen $\AA$ R, Falk RS, Knutsen KV, et al. Vitamin D deficiency and supplementation in pregnancy in a multiethnic population-based cohort. BMC Pregnancy Childbirth. 2016;16:7. doi:10.1186/s12884-016-0796-0

32. Qin LL, Lu FG, Yang SH, Xu HL, Luo BA. Does Maternal Vitamin D Deficiency Increase the Risk of Preterm Birth: A Meta-Analysis of Observational Studies. Nutrients. 2016;8(5):E301. doi:10.3390/nu8050301 
33. Lokki AI, Heikkinen-Eloranta J, Öhman H, Heinonen S, Surcel HM, Nielsen HS. Smoking during pregnancy reduces vitamin D levels in a Finnish birth register cohort [Epub ahead of print]. Public Health Nutr. 2019:1-5. doi: 10.1017/S1368980018003932

34. Manavi KR, Alston-Mills BP, Thompson MP, Allen JC. Effect of serum cotinine on vitamin D serum concentrations among american females with different ethnic backgrounds. Anticancer Res. 2015;35(2):1211-1218.

35. Holick MF. The vitamin D deficiency pandemic: Approaches for diagnosis, treatment and prevention. Rev Endocr Metab Disord. 2017;18(2):153-165. doi:10.1007/s11154017-9424-1

36. Hauta-Alus HH, Holmlund-Suila EM, Rita HJ, et al. Season, dietary factors, and physical activity modify 25 -hydroxyvitamin D concentration during pregnancy. Eur J Nutr. 2018;57(4):1369-1379. doi:10.1007/s00394-017-1417-z

37. Sankilampi U, Hannila ML, Saari A, Gissler M, Dunkel L. New population-based references for birth weight, length, and head circumference in singletons and twins from 23 to 43 gestation weeks. Ann Med. 2013;45(5-6):446-454.

doi:10.3109/07853890.2013.803739

38. Rothman KJ, Greenland S. Modern Epidemiology. 2nd ed. Philadelphia, PA: Lippincott-Raven; 1998

39. Freedman R, Hunter SK, Hoffman MC. Prenatal Primary Prevention of Mental Illness by Micronutrient Supplements in Pregnancy. Am J Psychiatry. 2018;175(7):607-619. doi:10.1176/appi.ajp.2018.17070836

40. Cui X, Pelekanos M, Liu PY, Burne TH, McGrath JJ, Eyles DW. The vitamin D receptor in dopamine neurons; its presence in human substantia nigra and its ontogenesis in rat midbrain. Neuroscience. 2013;236:77-87. doi:10.1016/j.neuroscience.2013.01.035 
41. Kesby JP, Turner KM, Alexander S, Eyles DW, McGrath JJ, Burne THJ. Developmental vitamin D deficiency alters multiple neurotransmitter systems in the neonatal rat brain. Int J Dev Neurosci. 2017;62:1-7. doi:10.1016/j.ijdevneu.2017.07.002

42. Burne TH, Becker A, Brown J, Eyles DW, Mackay-Sim A, McGrath JJ. Transient prenatal Vitamin D deficiency is associated with hyperlocomotion in adult rats. Behav Brain Res. 2004;154(2):549-555. doi:10.1016/j.bbr.2004.03.023

43. Eyles DW, Burne TH, McGrath JJ. Vitamin D, effects on brain development, adult brain function and the links between low levels of vitamin D and neuropsychiatric disease. Front Neuroendocrinol. 201;34(1):47-64. doi:10.1016/j.yfrne.2012.07.001

44. Berridge MJ. Vitamin D deficiency: infertility and neurodevelopmental diseases (attention deficit hyperactivity disorder, autism, and schizophrenia). Am J Physiol Cell Physiol. 2018;314(2):C135-C151. doi:10.1152/ajpcell.00188.2017

45. Forrest KY, Stuhldreher WL. Prevalence and correlates of vitamin D deficiency in US adults. Nutr Res. 2011;31(1):48-54. doi:10.1016/j.nutres.2010.12.001

46. Lee JM, Smith JR, Philipp BL, Chen TC, Mathieu J, Holick MF. Vitamin D deficiency in a healthy group of mothers and newborn infants. Clin Pediatr (Phila). 2007;46(1):4244. doi:10.1177/0009922806289311

47. García-Serna AM, Morales E. Neurodevelopmental effects of prenatal vitamin D in humans: systematic review and meta-analysis. Mol Psychiatry. 2019 Jan 29. doi: $10.1038 / \mathrm{s} 41380-019-0357-9$

48. Kotsi E, Kotsi E, Perrea DN. Vitamin D levels in children and adolescents with attention-deficit hyperactivity disorder (ADHD): a meta-analysis. Atten Defic Hyperact Disord. 2019 Sep;11(3):221-232. doi: 10.1007/s12402-018-0276-7. Epub 2018 Oct 26. 
49. Ross AC, Manson JE, Abrams SA, et al. The 2011 Dietary Reference Intakes for Calcium and Vitamin D: what dietetics practitioners need to know. J Am Diet Assoc. 2011;111(4):524-527. doi:10.1016/j.jada.2011.01.004

50. Dodds L, Woolcott CG, Weiler H, et al. Vitamin D Status and Gestational Diabetes: Effect of Smoking Status during Pregnancy. Paediatr Perinat Epidemiol. 2016;30(3):229-237. doi:10.1111/ppe.12278 
Figure 1. Distribution of Maternal 25(OH)D Levels by Offspring's AttentionDeficit/Hyperactivity Disorder Case-Control Status

Note: ${ }^{\mathrm{a}}$ The cut-points for the quintiles are based on the distribution in the control group 
Table 1. Covariates in Relation to Attention-Deficit/Hyperactivity Disorder (ADHD)

\begin{tabular}{|c|c|c|c|c|}
\hline & & $\begin{array}{l}\text { Cases, } \mathbf{n} \\
(\mathrm{N}=1067)\end{array}$ & $\begin{array}{l}\text { Controls, } n \\
(\mathrm{~N}=1067)\end{array}$ & $p$ \\
\hline \multirow{2}{*}{$\begin{array}{l}\text { Number of previous } \\
\text { births }\end{array}$} & 0 & $505(47.3 \%)$ & $419(39.3 \%)$ & \multirow[t]{2}{*}{.002} \\
\hline & $\geq 1$ & $562(52.7 \%)$ & $648(60.7 \%)$ & \\
\hline \multirow[t]{2}{*}{ Maternal smoking $^{\mathrm{a}}$} & No & $731(70.3)$ & $900(87.0)$ & \multirow[t]{2}{*}{$<.001$} \\
\hline & Yes & $309(29.7)$ & $135(13.0)$ & \\
\hline \multirow{2}{*}{$\begin{array}{l}\text { History of maternal } \\
\text { psychopathology } \mathrm{b}^{\mathrm{s}}\end{array}$} & No & $794(74.4 \%)$ & $940(88 \cdot 1 \%)$ & \multirow[t]{2}{*}{$<.001$} \\
\hline & Yes & $273(25.6)$ & $127(11.9)$ & \\
\hline \multirow{2}{*}{$\begin{array}{l}\text { History of maternal } \\
\text { substance abuse }\end{array}$} & No & $1010(94.7 \%)$ & $1052(98.6 \%)$ & \multirow[t]{2}{*}{$<.001$} \\
\hline & Yes & $57(5.3 \%)$ & $15(1.4 \%)$ & \\
\hline \multirow{2}{*}{$\begin{array}{l}\text { History of maternal } \\
\text { ADHD diagnosis }\end{array}$} & No & $1060(99.3 \%)$ & $1066(99.9 \%)$ & \multirow[t]{2}{*}{.07} \\
\hline & Yes & $7(0.7 \%)$ & $1(0.1 \%)$ & \\
\hline \multirow{2}{*}{$\begin{array}{l}\text { History of paternal } \\
\text { psychopathology }{ }^{\mathrm{e}, \mathrm{f}}\end{array}$} & No & $783(75.4 \%)$ & $920(86.8 \%)$ & \multirow[t]{2}{*}{$<.001$} \\
\hline & Yes & $256(24.6 \%)$ & $140(13.2 \%)$ & \\
\hline \multirow{2}{*}{$\begin{array}{l}\text { History of paternal } \\
\text { ADHD diagnosis }\end{array}$} & No & $1030(99.1 \%)$ & $1058(99.8 \%)$ & \multirow[t]{2}{*}{0.03} \\
\hline & Yes & $9(0.9 \%)$ & $2(0.2 \%)$ & \\
\hline \multirow[t]{2}{*}{ Gestational age (weeks) } & $<37$ & $101(9.5 \%)$ & $42(4.0 \%)$ & \multirow[t]{2}{*}{$<.001$} \\
\hline & $\geq 37$ & $962(90.5 \%)$ & $1020(96.1 \%)$ & \\
\hline \multirow{2}{*}{$\begin{array}{l}\text { Maternal immigrant } \\
\text { status }\end{array}$} & Born in Finland & $1043(97.8 \%)$ & $1059(99.3 \%)$ & \multirow[t]{2}{*}{0.004} \\
\hline & Not born in Finland & $24(2.3 \%)$ & $8(0.8 \%)$ & \\
\hline \multirow{2}{*}{$\begin{array}{l}\text { Maternal cotinine } \\
(\mathrm{ng} / \mathrm{ml})\end{array}$} & $<20$ & $770(72.2 \%)$ & $927(87.0 \%)$ & \multirow[t]{2}{*}{$<.001$} \\
\hline & $\geq 20$ & $297(27.84)$ & $139(13.0 \%)$ & \\
\hline \multirow[t]{5}{*}{ Maternal SES } & Upper white collar & $73(6 \cdot 8 \%)$ & $143(13.4 \%)$ & \multirow[t]{5}{*}{$<.001$} \\
\hline & Lower white collar & $466(43.7 \%)$ & $426(39.9 \%)$ & \\
\hline & Blue collar & $219(20.5 \%)$ & $191(17.9 \%)$ & \\
\hline & Others & $213(20.0 \%)$ & $165(15.5 \%)$ & \\
\hline & Missing & $136(12.8 \%)$ & $102(9.6 \%)$ & \\
\hline \multirow{3}{*}{$\begin{array}{l}\text { Birth weight for } \\
\text { gestational age }\end{array}$} & SGA $(<-2$ SD $)$ & $57(5.4 \%)$ & $24(2.3 \%)$ & \multirow{3}{*}{$<.001$} \\
\hline & $\mathrm{AGA}(-2 \mathrm{SD}$ to $+2 \mathrm{SD})$ & $969(91.2 \%)$ & $999(94.1 \%)$ & \\
\hline & $\operatorname{LGA}(>+2 \mathrm{SD})$ & $36(3.4 \%)$ & $39(3.7 \%)$ & \\
\hline \multirow{5}{*}{$\begin{array}{l}\text { Season of blood } \\
\text { collection }\end{array}$} & Winter (Dec-Feb) & $298(27.9 \%)$ & $288(27.0 \%)$ & \multirow[t]{4}{*}{0.86} \\
\hline & Spring (Mar-May) & $291(27.3 \%)$ & $307(28.8 \%)$ & \\
\hline & Summer (Jun-Aug) & $228(21.4 \%)$ & $220(20.6 \%)$ & \\
\hline & Autumn (Sep-Nov) & $250(23.4 \%)$ & $252(23.6 \%)$ & \\
\hline & & Mean (SE) & Mean (SE) & \\
\hline \multicolumn{2}{|l|}{ Maternal age (years) } & $27.9(0.18)$ & $29.5(0.16)$ & $<.001$ \\
\hline \multicolumn{2}{|c|}{ Gestational week of blood draw } & $10.7(0.11)$ & $10.6(0.10)$ & .54 \\
\hline
\end{tabular}

Note: Boldface type indicates. $\mathrm{SE}=$ standard error; $\mathrm{SES}=$ socioeconomic status.

${ }^{a}$ Maternal smoking missing for 27 cases and 32 controls

b International Classification of Diseases, Revision 8 (ICD-8) (291-308), ICD-9 (291-316) or ICD-10 (F10-99), excluding mental retardation (F70-79), ADHD diagnosis (ICD-10: F90.X or ICD-9: 314.X) and substance abuse diagnosis (ICD-8: 291, 303, 304, ICD-9: 291, 292, 303, 304, 305 or ICD-10: F10-19)

${ }^{\mathrm{c}} \underline{\mathrm{ICD}-8}(291,303,304), \operatorname{ICD}-9(291,292,303,304,305)$ or ICD-10 (F10-19)

d ICD-10: F90.X or ICD-9: 314.X

${ }^{\mathrm{e}} I C D-8$ (291-308), ICD-9 (291-316) or ICD-10 (F10-99), excluding mental retardation (F7079) and ADHD diagnosis (ICD-10: F90.X or ICD-9: 314.X)

${ }^{\mathrm{f}}$ Paternal psychopathology and paternal ADHD diagnosis missing for 28 cases and 7 controls

${ }^{\mathrm{g}}$ Gestational age missing for 4 cases and 5 controls 
${ }^{\mathrm{h}}$ Birth weight for gestational age missing for 5 cases and 5 controls. 
Table 2. Covariates in Relation to Maternal Serum 25- hydroxyvitamin D (25(OH)D) Among Controls

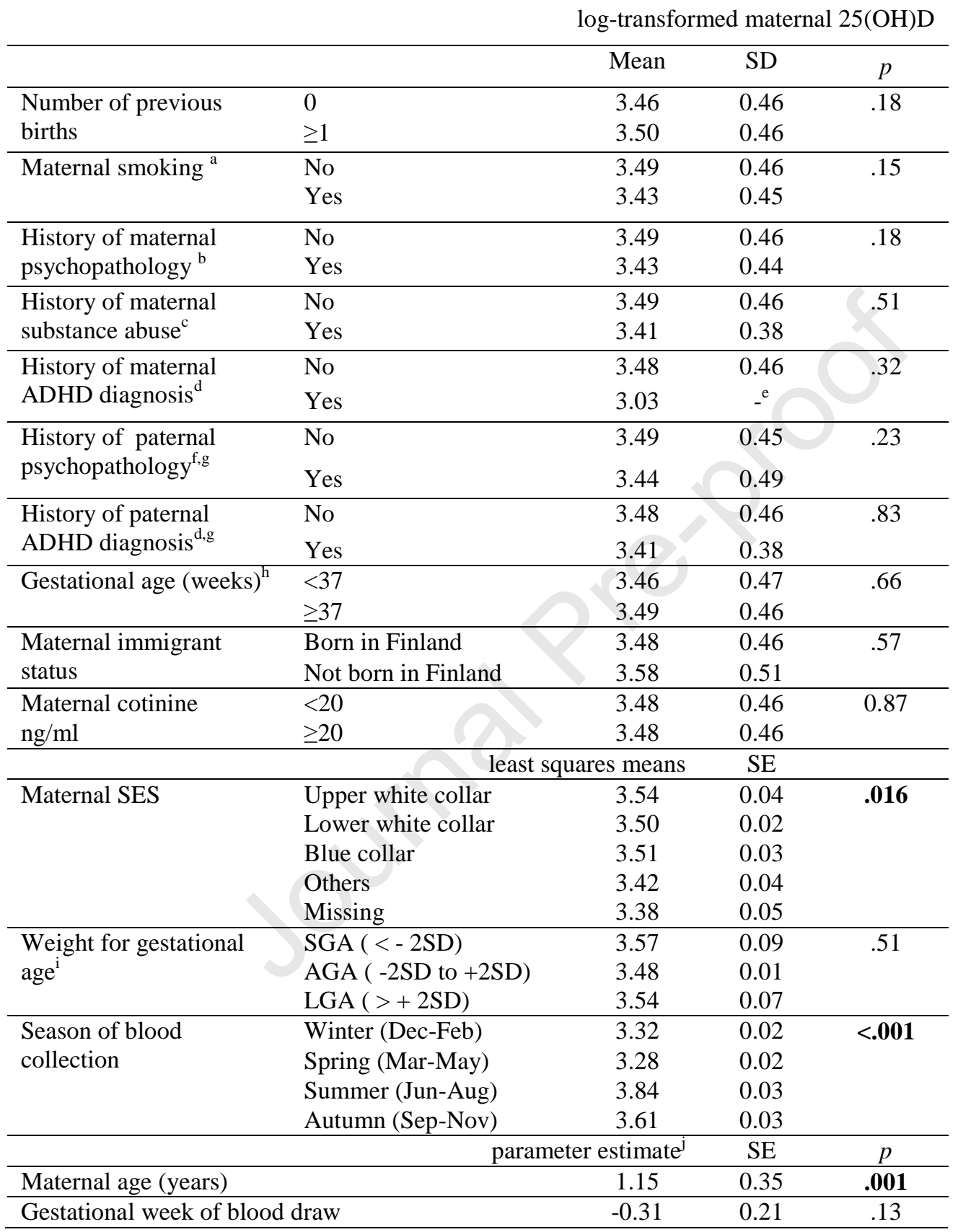

Note: $\mathrm{ADHD}=$ attention-deficit/hyperactivity disorder; ICD = International Classification of Diseases. $\mathrm{SE}=$ standard error; $\mathrm{SES}=$ socioeconomic status.

${ }^{a}$ Maternal smoking missing for 27 cases and 32 controls

${ }^{\mathrm{b}} I C D-8$ (291-308), ICD-9 (291-316) or $I C D-10$ (F10-99), excluding intellectual disability (F70-79), ADHD diagnosis (ICD-10: F90.X or ICD-9: 314.X) and substance abuse diagnosis (ICD-8: 291, 303, 304, ICD-9: 291, 292, 303,304,305 or ICD-10: F10-19)

${ }^{c} I C D-8(291,303,304)$, ICD-9 $(291,292,303,304,305)$ or $I C D-10$ (F10-19)

${ }^{\mathrm{d}} I C D-10:$ F90.X or $I C D-9: 314 . \mathrm{X}$ 
${ }^{\mathrm{f}}$ ICD-8 (291-308), ICD-9 (291-316) or ICD-10 (F10-99), excluding intellectual disability (F70-79) and ADHD diagnosis (ICD-10: F90.X or ICD-9: 314.X)

${ }^{\mathrm{g}}$ Paternal psychopathology and paternal ADHD diagnosis missing for 7 controls

${ }^{\mathrm{h}}$ Gestational age missing for 5 controls, ${ }^{\mathrm{i}}$ Birth weight for gestational age missing for 5 controls

e only one observation,

${ }^{\mathrm{j}}$ regression analysis 
Table 3. Association Between Maternal Serum 25-hydroxyvitamin D (25[OH]D) and Attention-Deficit/Hyperactivity Disorder in Offspring

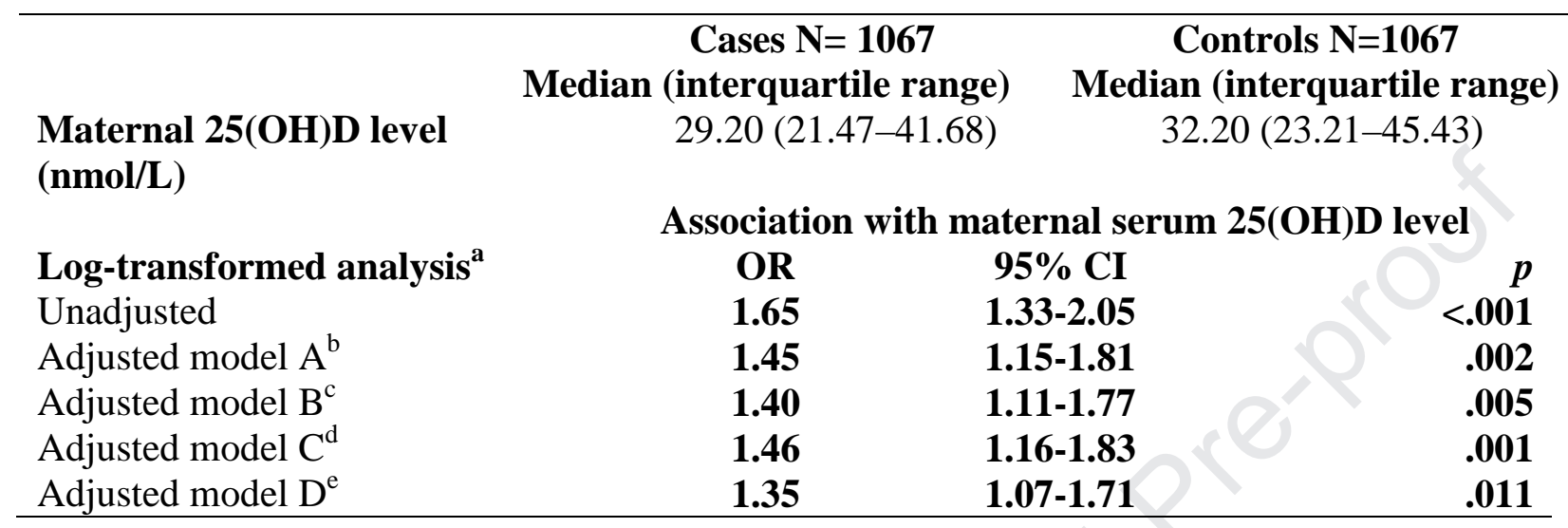

Note: $\mathrm{OR}=$ odds ratio; $\mathrm{SES}=$ socioeconomic status.

${ }^{a}$ For one unit decrease, continuous model

${ }^{\mathrm{b}}$ Adjusted for maternal SES and maternal age

${ }^{\mathrm{c}}$ Adjusted for maternal SES, maternal age and maternal psychiatric history (International Classification of Diseases, Revision 8 [ICD-8] (291308), ICD-9 (291-316) or ICD-10 (F10-99), excluding mental retardation (F70-79), ADHD diagnosis (ICD-10: F90.X or ICD-9: 314.X) and substance abuse diagnosis (ICD-8: 291, 303, 304, ICD-9: 291, 292, 303,304,305 or ICD-10: F10-19)

d Adjusted for maternal SES, maternal age and child's weight for gestational age

${ }^{\mathrm{e}}$ Adjusted for maternal SES, maternal age and maternal cotinine ( $<20$ or $\geq 20 \mathrm{ng} / \mathrm{ml}$ ) 


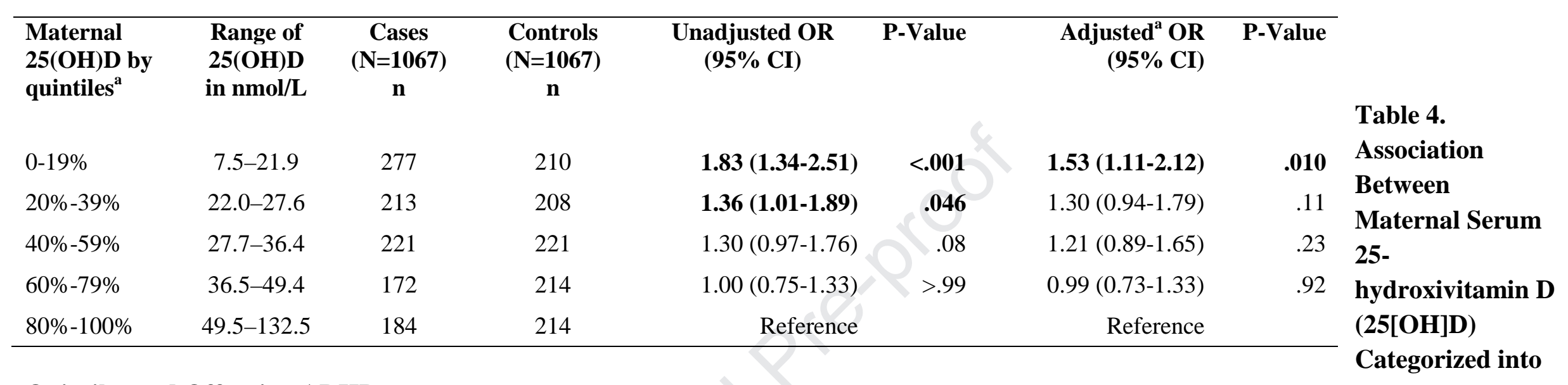

Quintiles and Offspring ADHD 


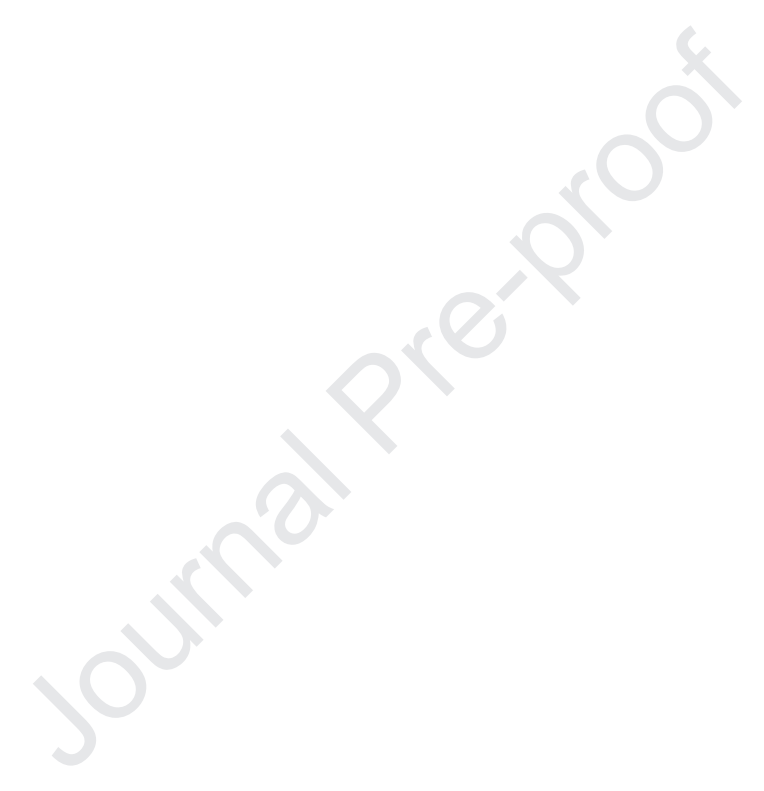




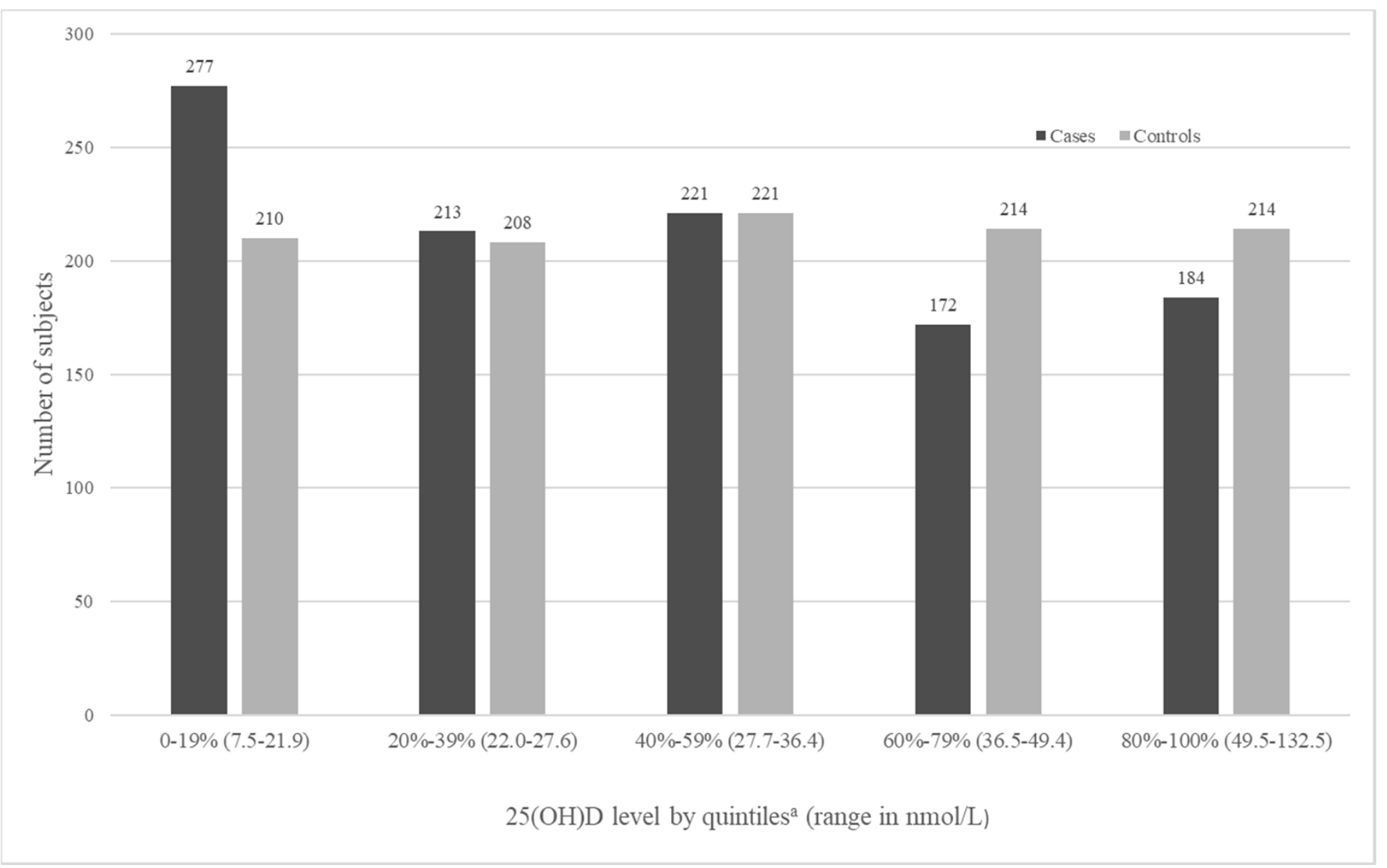




\section{Section 3:}

\section{Funding, acknowledgments, and financial disclosures of all authors}

\section{Funding:}

This research was funded by the National Institute of Environmental Health Sciences (Grant number: 5R01ES028125), the Academy of Finland Flagship Program (decision number: 320162), the Strategic Research Council at the Academy of Finland (decision number: 303581), the National Institutes of Health (Grant number:1RO1ES028125-01) and the Academy of Finland Health from Cohorts and Biobanks Program (decision number: 308552), the Pediatric Research Foundation (M.S.), the Finnish Medical Foundation (M.S., D.G.), the University of Turku Graduate School (M.S.), the Finnish Brain Foundation (M.S.), The State Research Funding (M.S.) and the Brain and Behavior Research Foundation (D.G.).

\section{Financial disclosures}

The authors have no financial disclosures nor conflicts of interest to declare.

\section{Acknowledgements}

This research was supported by the INVEST Research Flagship, APEX Research Consortium and PSYCOHORTS consortium. 